\section{Neuroendocrine Regulation of the Corpus Luteum in the Human Evidence for Pulsatile Progesterone Secretion}

Marco Filicori, James P. Butler, and William F. Crowley, Jr. Vincent Research Laboratories, Massachusetts General Hospital, Boston, Massachusetts 02114; Harvard School of Public Health, Boston, Massachusetts 02115 bstract. The pattern of episodic gonadotropin release was studied in 15 normal female volunteers during the luteal phase of the menstrual cycle with $24 \mathrm{~h}$ of blood sampling for follicle-stimulating hormone (FSH) and luteinizing hormone (LH) levels at 10 -min intervals. Six subjects (two in the early, two in the mid-, and two in the late luteal phase) also had each of these specimens processed for progesterone levels.

A progressive slowing of $\mathrm{LH}$ pulsations was present across the luteal phase with the mean LH pulse frequency declining from 15.2 pulses/24 $\mathrm{h}$ in the early to $8.4 / 24 \mathrm{~h}$ in the late luteal phase. A trend towards reduction in the amplitude of $\mathrm{LH}$ pulses was also observed $(12.3 \pm 2.2 \mathrm{SD}$ $\mathrm{mIU} / \mathrm{ml}$ in the early vs. $8.6 \pm 3.4 \mathrm{mIU} / \mathrm{ml}$ in the late luteal phase; NS). In addition, LH pulses of heterogeneous amplitude were identified during the same 24-h study. The mean \pm SD of the larger and of the smaller $\mathrm{LH}$ pulses was $16.9 \pm 4.7$ and $2.3 \pm 1.0 \mathrm{mIU} / \mathrm{ml}$, respectively $(P<0.001)$. While the slowing of the frequency of all LH pulses correlated well $(r=0.80, P<0.001)$ with the day of the luteal phase and poorly with the actual plasma progesterone levels, the incidence of the small LH pulses was highest in the mid-luteal phase and correlated well with the mean progesterone plasma levels $(r=0.63, P<0.01)$.

In the early luteal phase, the pattern of progesterone secretion was stable over the 24-h studies and showed no

Dr. Filicori was the recipient of a travel grant from the Fulbright-Hays Program and his present address is Department of Reproductive Medicine, University of Bologna, Via Massarenti 13, Bologna, Italy. Address reprint requests to Dr. Crowley, Vincent Research Laboratories, Massachusetts General Hospital, Boston, MA 02114.

Received for publication 6 July 1983 and in revised form 16 February 1984.

J. Clin. Invest.

(c) The American Society for Clinical Investigation, Inc. 0021-9738/84/06/1638/10 \$1.00

Volume 73, June 1984, 1638-1647 relationship to episodic $\mathrm{LH}$ release. In contrast, in the mid- and late luteal phase, plasma progesterone concentrations rapidly fluctuated during the 24-h studies from levels as low as 2.3 to peaks of $40.1 \mathrm{ng} / \mathrm{ml}$, often within the course of minutes. Progesterone increments closely attended episodes of $\mathrm{LH}$ release, as documented by the significant $(P<0.05)$ cross-correlation between LH and progesterone levels, at time lags of 25-55 $\mathrm{min}$.

The results of this study indicate that in the human luteal phase: $(a)$ the frequency of pulsatile release of LH declines progressively and correlates well with the duration of exposure to progesterone; $(b)$ the amplitude of $\mathrm{LH}$ pulses varies with the appearance of an increased percentage of smaller pulses correlating well with the acute level of progesterone; $(c)$ in the early luteal phase, the pattern of progesterone secretion is stable; $(d)$ in the midand late luteal phase, progesterone secretion is episodic, and correlates with LH pulsatile release; and $(e)$ single progesterone estimations in the mid- and late luteal phase do not accurately reflect corpus luteum adequacy.

\section{Introduction}

The corpus luteum $(\mathrm{CL})^{1}$ is an atypical endocrine organ whose short life-span appears to be "programmed" and only partly influenced by external factors. This functional feature is present in greater or lesser extent in all species (1) and the contribution of hormonal factors upon CL activity has not yet been precisely defined. Although luteinizing hormone $(\mathrm{LH})$ is considered to be a luteotropic agent in the human and the subhuman primate, the exact role of $\mathrm{LH}$ in the formation, support, and demise of the CL is still controversial (2). Moreover, the episodic release of gonadotropins in the human is continuously modified across

1. Abbreviations used in this paper: $\mathrm{CL}$, corpus luteum; $\mathrm{E}_{2}$, estradiol; ELP, early luteal phase; FSH, follicle-stimulating hormone; GnRH, gonadotropin-releasing hormone; hCG, human chorionic gonadotropin; LH, luteinizing hormone; LLP, late luteal phase; MLP, mid-luteal phase; $P$, progesterone; RIA, radioimmunoassay. 
the menstrual cycle. Although it was previously established (3, 4) that LH pulses are less frequent and of larger amplitude in the luteal phase than in the follicular phase, little is known of the spectrum of the modifications of these parameters in normal subjects, the precise timing of their occurrence, and the gonadal effects of this modulation of the pituitary signal. This study was designed to explore the pattern of gonadotropin and progesterone (P) secretion across the luteal phase, analyze the modulation of LH pulse amplitude and frequency, and examine the effect of these changes upon the secretory activity of the human CL.

\section{Methods}

15 paid female volunteers participated in the study. Each subject had a history of regular $27-32-d$ menstrual cycles and body weight $\pm 15 \%$ of average (5). The volunteers were not involved in intensive physical exercise and were not receiving any medications. On physical examination no evidence of hirsutism, galactorrhea, or genital abnormalities was noticed. Plasma prolactin levels were $<15 \mathrm{ng} / \mathrm{ml}$ in each, and normal luteal function was documented in the previous menstrual cycle by basal body temperature charts and mid-luteal phase $P$ levels $>6 \mathrm{ng} / \mathrm{ml}$.

Daily blood samples were obtained for one complete menstrual cycle and were processed for the determination of gonadotropins, estradiol $\left(E_{2}\right)$, and $P$ levels. On one day of the luteal phase of this cycle, each subject was admitted to the Clinical Research Center of the Massachusetts General Hospital and $3 \mathrm{ml}$ blood samples were withdrawn at 10-min intervals for 24 consecutive hours. During the 24-h study, five additional plasma samples were drawn at $0,6,12,18$, and $24 \mathrm{~h}$ for the determination of $E_{2}$ and $P$. Five subjects were studied in the early luteal phase (ELP, days 1-4 post LH mid-cycle surge), five in the mid-luteal phase (MLP, days 5-9 post LH mid-cycle surge), and five in the late luteal phase (LLP, days 10-14 post LH mid-cycle surge). All samples from the 24$\mathrm{h}$ studies were processed for $\mathrm{LH}$ and follicle-stimulating hormone (FSH) determinations. Each plasma sample from six of the 24-h studies (Subjects $A$ and $B$ in the ELP, C and D in the MLP, and E and F in the LLP) was also assayed for $P$.

All samples from each subject (daily samples and 24-h study) were run in the same double antibody radioimmunoassay (RIA) for LH and FSH determinations. The LH and FSH antisera were purchased from Serono-Biodata Diagnostics Division (Rome, Italy). Human chorionic gonadotropin (hCG) was labelled and used as a tracer in the LH assay.
Values were expressed as equivalents of the 2nd International Reference Preparation-human menopausal gonadotropin $(\mathrm{mIU} / \mathrm{ml})$. The sensitivity (95\% confidence limit) of the LH and FSH assays varied between 0.8 and $1.6 \mathrm{mIU} / \mathrm{ml}$ of plasma. The precision of the gonadotropin assays was estimated at 20,50 , and $80 \%\left(B / \mathrm{B}_{0}\right)$ displacement of the standard curve. The quality control characteristics of the gonadotropin assays reported herein are shown in Table $I$.

$P$ concentrations were estimated by RIA. All plasma samples from each 24-h study were processed within the same assay. Several standard curves and quality controls were interspersed within each assay to monitor precision. Separation of bound/free was carried out with charcoal in two successive steps, each including half of the assay samples in order to contain the time of the charcoal addition procedure to within 25$30 \mathrm{~min}$. The intrassay and interassay coefficient of variation for the $P$ assay are shown in Table I. To observe the effect of different bound/ free separation procedures, one of the 24-h studies was processed twice for P, the second time utilizing Staphylococcal Protein A (6) as a separation method. The result of the two $P$ assays were almost perfectly superimposable and no differences in the pattern of secretion were identified with the use of a different separation procedure (data not shown).

Several algorithms exist in the literature for computer-assisted pulse analysis $(4,7,8)$. All of these methods of analysis are essentially threshold detectors, i.e., a hormone fluctuation is considered a pulse when its amplitude exceeds a predetermined value. For our study we chose to apply the Santen and Bardin (4) approach because of the experience accumulated with this method by other investigators, as well as for its ease and simplicity of use. We also reanalyzed our data with the Pulsar program by Merriam and Wachter (7) and found no significant difference in trends and correlations, although the actual number of pulses detected varied modestly. We implemented a slightly modified version of the Santen and Bardin program on a VAX 11/780 computer (Digital Equipment Corp., Marlboro, MA), where LH pulsations were defined as increments of plasma levels $>1 \mathrm{mIU} / \mathrm{ml}$ which exceeded the previous nadir by $20 \%$ or more. The $\mathrm{LH}$ interpulse interval represents the time between two consecutive LH pulses. The amplitude of a pulse was defined as the difference between the highest value in the pulse and the preceding nadir. Cross-correlation analysis (9) was utilized to define the temporal relationship between $\mathrm{LH}, \mathrm{FSH}$, and $\mathrm{P}$ data series during each 24-h study. A $P$ value $<0.05$ was assumed as significance level for the cross-correlation. Two-tailed $t$ statistics and linear correlation analysis were utilized as indicated.

Table I. Radioimmunoassay Quality Control Data

\begin{tabular}{|c|c|c|c|c|c|c|}
\hline & \multicolumn{2}{|l|}{ LH } & \multicolumn{2}{|l|}{ FSH } & \multicolumn{2}{|l|}{$\mathbf{P}$} \\
\hline & Intraassay CV & Interassay CV & Intraassay $\mathrm{CV}$ & Interassay $\mathrm{CV}$ & Intraassay $\mathrm{CV}$ & Interassay $\mathrm{CV}$ \\
\hline & $\%$ & $\%$ & $\%$ & $\%$ & $\%$ & $\%$ \\
\hline \multicolumn{7}{|c|}{$\begin{array}{l}\text { Displacement } \\
\qquad\left(\mathrm{B} / \mathrm{B}_{0} ; \%\right)\end{array}$} \\
\hline 80 & 11.3 & 11.8 & 9.8 & 13.2 & 17.3 & 16.6 \\
\hline 50 & 6.6 & 9.4 & 7.5 & 7.8 & 14.6 & 8.1 \\
\hline 20 & 5.6 & 12.0 & 6.3 & 9.0 & 16.1 & 11.2 \\
\hline
\end{tabular}

Quality control characteristics of the LH, FSH, and $\mathrm{P}$ assays. Values are expressed as percent coefficient of variation (CV) at different levels of displacement $\left(\mathrm{B} / \mathrm{B}_{0}\right)$ of the assay standard curve. 
Table II. Gonadotropin and Sex Steroid Levels Across the Luteal Phase

\begin{tabular}{|c|c|c|c|c|c|c|}
\hline \multirow{3}{*}{ 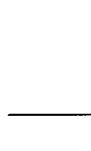 } & \multicolumn{3}{|l|}{ LH } & \multirow[b]{2}{*}{ FSH: plasma levels } & \multirow[b]{2}{*}{$E_{2}:$ plasma levels } & \multirow[b]{2}{*}{ F: plasma levels } \\
\hline & Plasma levels & Pulse amplitude & Interpulse interval & & & \\
\hline & $\mathrm{mIU} / \mathrm{ml}$ & $m I U / m l$ & $\min$ & $m I U / m l$ & $p g / m l$ & $n g / m l$ \\
\hline ELP & $21.5+/-5.2$ & $12.3+/-2.2$ & $99+/-20$ & $8.5+/-5.4$ & $95+/-14$ & $2.6+/-1.8$ \\
\hline MLP & $6.9+/-1.9$ & $10.7+/-4.6$ & $162+/-33$ & $5.8+/-1.2$ & $156+/-3$ & $19.4+/-6.4$ \\
\hline LLP & $6.8+/-1.2$ & $8.6+/-3.4$ & $173+/-20$ & $4.4+/-2.2$ & $88+/-38$ & $7.0+/-4.8$ \\
\hline
\end{tabular}

Plasma concentrations of $\mathrm{LH}, \mathrm{FSH}, \mathrm{E}_{2}$, and $\mathrm{P}$, and frequency and amplitude characteristics of $\mathrm{LH}$ pulsations in the different stages of the menstrual cycle. Values are expressed as mean $+/-$ standard deviation.

\section{Results}

All the subjects studied had endocrinologically normal menstrual cycles with mid-luteal $P$ levels which exceeded $9 \mathrm{ng} / \mathrm{ml}$ and a luteal phase duration $>13 \mathrm{~d}$.

Gonadotropins (Table II). Mean LH levels decreased from $21.5 \pm 5.2 \mathrm{mIU} / \mathrm{ml}($ mean $\pm \mathrm{SD})$ in the ELP to $6.9 \pm 1.9 \mathrm{mIU} / \mathrm{ml}$ in the MLP $(P<0.01)$ and $6.8 \pm 1.2 \mathrm{mIU} / \mathrm{ml}$ in the LLP $(P$ $<0.01$ between ELP and LLP but NS between MLP and LLP). The frequency of $\mathrm{LH}$ pulsatile discharge changed across the luteal phase as the mean $\mathrm{LH}$ interpulse interval progressively increased from $99 \pm 20 \mathrm{~min}$ in the ELP (15.2 pulses $/ 24 \mathrm{~h}$ ) to $162 \pm 33 \mathrm{~min}$ in the MLP $(9.2$ pulses $/ 24 \mathrm{~h})$ and $173 \pm 20 \mathrm{~min}$ in the LLP $(8.4$ pulses $/ 24 \mathrm{~h})$. This difference in the mean LH interpulse interval achieved significance between the ELP and the MLP $(P<0.05)$ and the LLP $(P<0.01)$, but not between the MLP and the LLP. However, the mean LH interpulse interval was positively correlated $(r=0.80, P<0.001)$ with the day of the luteal phase (Fig. 1). On the other hand, no significant correlation existed between the mean $P$ levels on the day of the 24-h study and the mean LH interpulse interval.

The mean amplitude of LH pulses progressively declined from $12.3 \pm 2.2 \mathrm{mIU} / \mathrm{ml}$ in the ELP to $10.7 \pm 4.6 \mathrm{mIU} / \mathrm{ml}$ in the MLP and $8.6 \pm 3.4 \mathrm{mIU} / \mathrm{ml}$ in the LLP. Although a clear trend was evident, none of these changes was statistically significant. In the same 24-h period, heterogeneous LH pulses could be identified (Fig. 2) and divided arbitrarily into pulses of $<5 \mathrm{mIU} /$ $\mathrm{ml}$ and $>5 \mathrm{mIU} / \mathrm{ml}$ amplitude. When this was done the mean \pm SD amplitude of the smaller pulses and larger pulses was $2.3 \pm 1.0$ and $16.9 \pm 4.7 \mathrm{mIU} / \mathrm{ml}$, respectively $(P<0.001)$. The incidence (Fig. 3) of smaller ( $<5 \mathrm{mIU} / \mathrm{ml}$ amplitude) $\mathrm{LH}$ pulses increased from an average of $19 \%$ of the total pulses observed in the ELP to $52 \%$ in the MLP, and then declined slightly in the LLP (45\%). A bimodal fashion in the distribution of LH pulse amplitude was present in the MLP, when $52 \%$ of $\mathrm{LH}$ pulses were $<5 \mathrm{mIU} / \mathrm{ml}, 17 \%$ had an amplitude of 5-15 mIU/ $\mathrm{ml}$, and $30 \%$ were $>15 \mathrm{mIU} / \mathrm{ml}$. The increase in the incidence of $<5 \mathrm{mIU} / \mathrm{ml} \mathrm{LH}$ pulses and the decrement of $5-15 \mathrm{mIU} / \mathrm{ml}$ LH pulses was significant $(P<0.05)$ between the ELP and the MLP (Fig. 3). The incidence of smaller LH pulses was positively correlated $(r=0.63, P<0.01)$ to plasma $P$ concentrations on the day of the study (Fig. 1), but not to the day of the luteal phase in which the 24-h study was executed.

The mean FSH plasma levels decreased from 8.5 \pm 5.4 to $5.8 \pm 1.2 \mathrm{mIU} / \mathrm{ml}$ in the MLP and $4.4 \pm 2.2 \mathrm{mIU} / \mathrm{ml}$ in the LLP. None of these changes was statistically significant. Although the
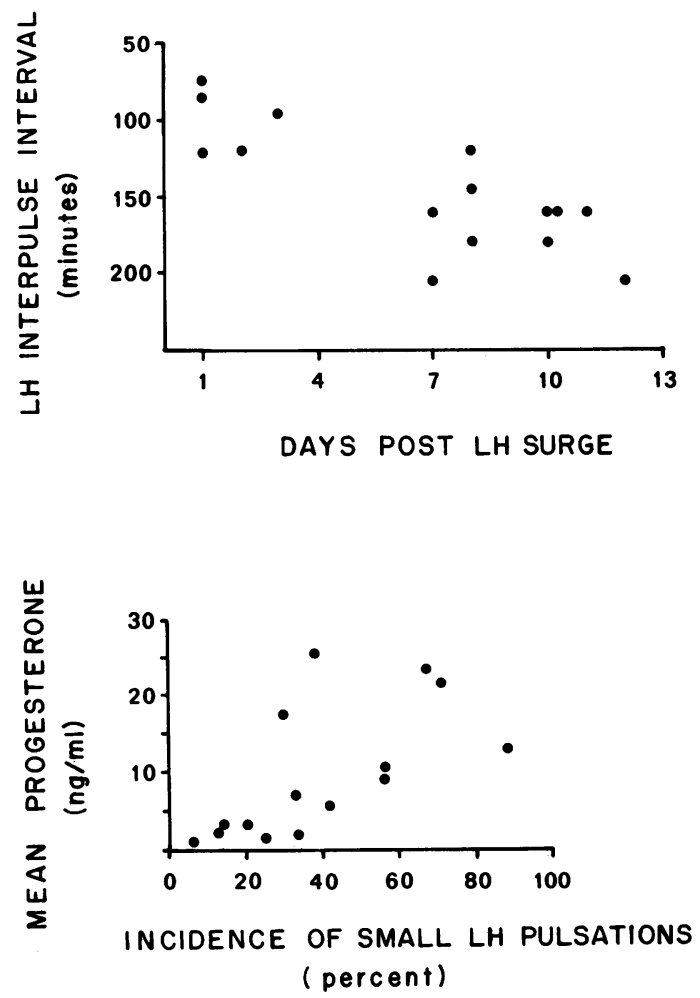

Figure 1. Patterns of LH pulse amplitude and frequency modulation of the human luteal phase. The LH interpulse interval is positively correlated $(r=0.80, P<0.001)$ with the day of the luteal phase (post-LH surge) when the 24-h frequent sampling was performed (upper panel). The percent incidence of $\mathrm{LH}$ pulsations of smaller amplitude $(<5 \mathrm{mIU} / \mathrm{ml})$ is positively correlated $(r=0.63, P<0.01)$ with the mean plasma levels of $P$ on the day of the 24-h study (lower panel). 


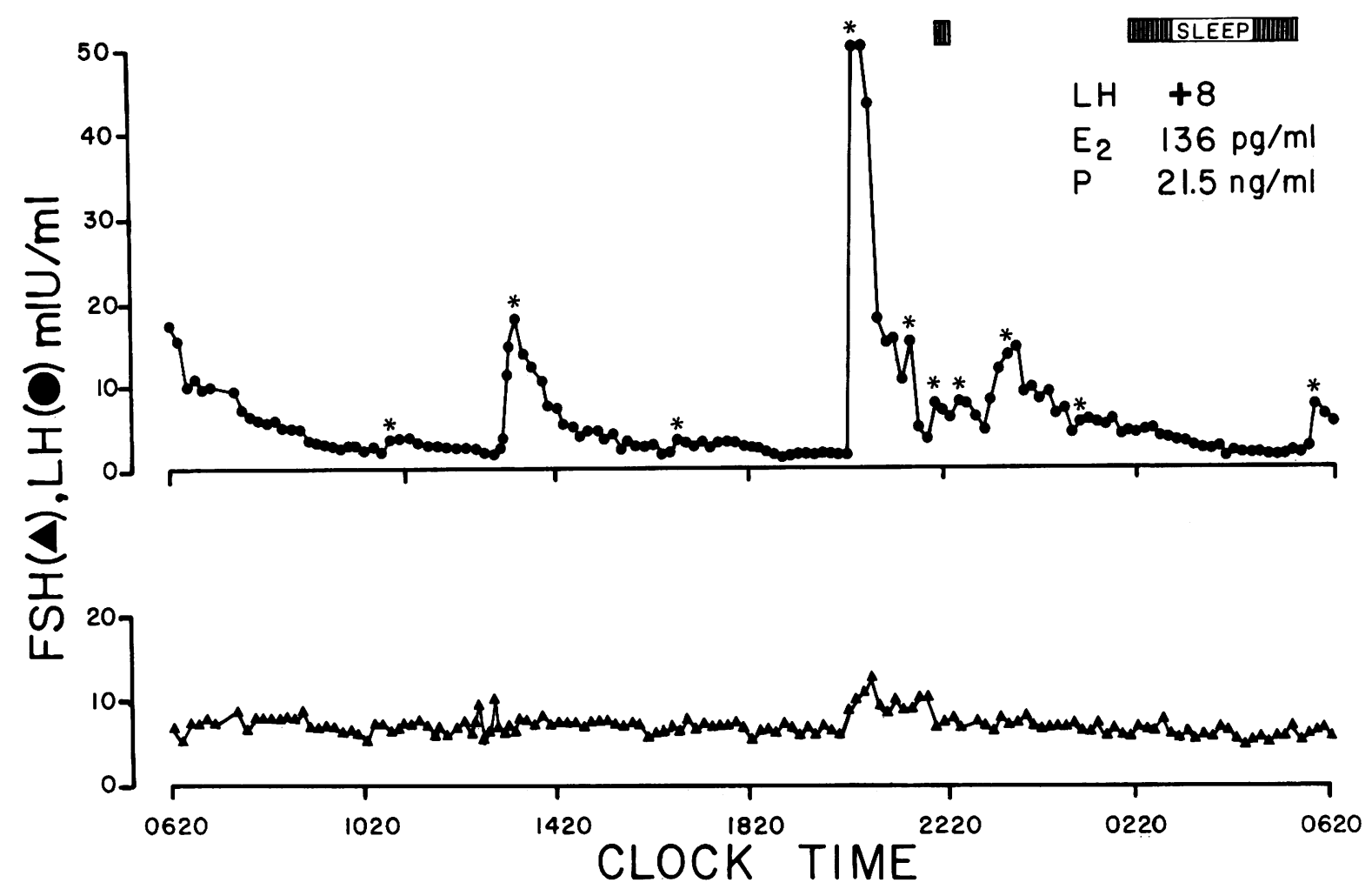

Figure 2. Plasma concentrations of LH (๑) and FSH (^) during $24 \mathrm{~h}$ of blood sampling at 10 -min intervals in a normal volunteer in the MLP (LH midcycle surge $+8 d=L H+8)$. The mean $E_{2}$ and $P$ concentrations on the day of the study are shown in the upper right corner of the graph. Asterisks indicate significant LH pulsations.

direct identification of FSH pulses was hampered by the small amplitude of its fluctuations, a significantly $(P<0.05)$ positive cross-correlation existed between the LH and FSH data series from the pulsation studies of each subject. The time lag of the cross-correlation was 0 min in most subjects ( 13 out of 15$)$ and at $+10 \mathrm{~min}$ in the remaining two subjects.

Sex steroids (Table II). Mean P levels increased from 2.6 \pm 1.8 in the ELP to $19.4 \pm 6.4 \mathrm{ng} / \mathrm{ml}$ in the MLP $(P<0.01)$ and declined to $7.0 \pm 4.8 \mathrm{ng} / \mathrm{ml}$ in the LLP (NS between ELP and LLP, $P<0.05$ between MLP and LLP). P secretion in the ELP was stable at a mean level of 1.0 and $6.2 \mathrm{ng} / \mathrm{ml}$ in subject $A$ and B, respectively (Fig. 4). No significant cross-correlation was present between LH and P or between FSH and P levels at any time lag in the ELP. The subjects studied during the MLP and LLP showed a remarkably different pattern of secretion. In the MLP (Fig. 5), P levels fluctuated widely from levels as low as $4.1 \mathrm{ng} / \mathrm{ml}$ to peaks of $40.1 \mathrm{ng} / \mathrm{ml}$. In these two subjects, a positive cross-correlation between $\mathrm{LH}$ and $\mathrm{P}$ at time lag of 20-30 min (subject C) and 30-40 min (subject D) was present. A positive cross-correlation was also observed between FSH and P levels at time lags of 20-30 $\mathrm{min}$ (C) and $30 \mathrm{~min}$ (D). Direct observation of the hormone levels indicates that an initial response to in-
Sleep periods are shown as hatched bars in upper portion of the panel. This subject is representative of the heterogeneity in LH pulse amplitude encountered in the MLP. Although clear-cut episodic secretion of FSH is not always identifiable, a large FSH pulse is present at time $2100 \mathrm{~h}$ and corresponds with a large LH pulse.

creasing LH levels, as reflected by the change of P levels, was already present after 10-20 min. Mean plasma $P$ levels in the LLP were 9.2 and $10.6 \mathrm{ng} / \mathrm{ml}$ for subjects $E$ and $F$, respectively. Similar to the MLP, marked plasma $P$ variations were present over the 24-h study in the LLP with individual samples ranging between 2.3 and $27.2 \mathrm{ng} / \mathrm{ml}$ (Fig. 6). Cross-correlation analysis between $\mathrm{LH}$ and $\mathrm{P}$ levels provided significant results at 50-60 min and 30-50 min for subjects $E$ and $F$, respectively, with initial $P$ increments already present $10-20$ min following the initiation of the LH pulses. FSH and P data series from the pulsation studies were also correlated in the LLP at time lags $30 \mathrm{~min}(\mathrm{E})$ and $20-30 \mathrm{~min}(\mathrm{~F})$.

Mean plasma $E_{2}$ levels were $95 \pm 14 \mathrm{pg} / \mathrm{ml}$ in the ELP, $156 \pm 3$ $\mathrm{pg} / \mathrm{ml}$ in the MLP $(P<0.001)$, and $88 \pm 38 \mathrm{pg} / \mathrm{ml}$ in the LLP (NS between ELP and LLP, $P<0.02$ between MLP and LLP). The mean plasma levels of $E_{2}$ and $P$ on the day of the 24-h study (five determinations) were highly correlated ( $r=0.81$, $P<0.001$ ). $\mathrm{E}_{2}$ levels did not correlate with $\mathrm{LH}$ interpulse intervals nor with the mean amplitude of LH pulses. However, a positive correlation $(r=0.60, P<0.05)$ existed between the incidence of $\mathrm{LH}$ pulses of smaller amplitude $(<5 \mathrm{mIU} / \mathrm{ml})$ and mean $\mathrm{E}_{2}$ levels. 

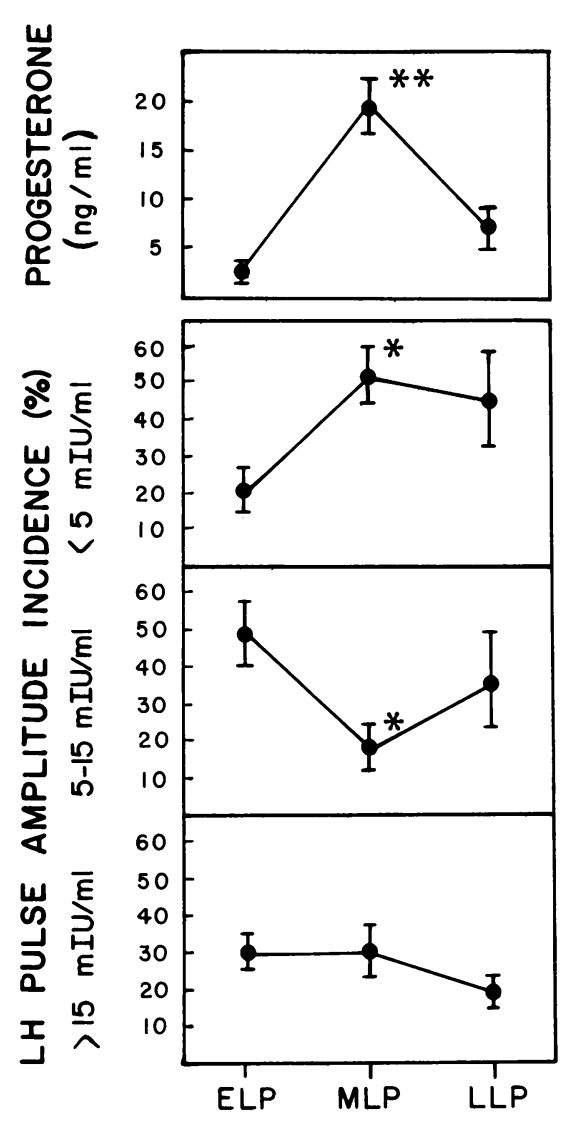

\section{STAGE OF LUTEAL PHASE}

Figure 3. Changes in LH pulse amplitude distribution across the human luteal phase. The changes in concentration of plasma $P$ are shown in the upper panel. The relative incidence of $\mathrm{LH}$ pulses of different amplitudes ( $<5 \mathrm{mIU} / \mathrm{ml}, 5-15 \mathrm{mIU} / \mathrm{ml},>15 \mathrm{mIU} / \mathrm{ml}$ ) are shown in the lower three panels. The incidence of LH pulses of smaller amplitude $(<5 \mathrm{mIU} / \mathrm{ml})$ significantly increases from the ELP to the MLP, while at the same time the incidence of intermediate size $\mathrm{LH}$ pulses $(5-15 \mathrm{mIU} / \mathrm{ml})$ decreases significantly, in parallel with the increment in plasma $P$ concentration. All values are expressed as mean \pm SE. *, $P<0.05$; **, $P<0.01$.

\section{Discussion}

This study demonstrates that the frequency of pulsatile LH release declines progressively across the human luteal phase. Furthermore, plasma $P$ levels also fluctuate widely in the MLP and LLP, and the patterns of LH and P blood concentrations are significantly correlated. These findings suggest that the human $C L$ responds to intermittent pituitary stimulation with episodic $P$ secretion.

Previous investigations of pulsatile gonadotropin release in the human menstrual cycle $(3,4)$ have indicated that the frequency of LH discharge is slower (about every $4 \mathrm{~h}$ ) and that the amplitude of each pulse is larger in the luteal phase than in the follicular phase. Our study extends these observations and suggests a more complex interaction of sex steroid secretion and gonadotropin modulation during the luteal phase. A progressive slowing of the LH pulse frequency was noted across the luteal phase with the LH interpulse interval increasing from $99 \mathrm{~min}$ in the ELP to $173 \mathrm{~min}$ by the LLP. This change in LH pulse frequency was correlated with the day of the luteal phase when each subject was studied but not with the mean level of $P$ on that day, suggesting that it was the duration of exposure to $P$ and not its absolute level which produced this change. The possible mechanisms by which $\mathrm{P}$ may effect this slowing of $\mathrm{LH}$ pulse frequency are still unclear. $P$ has been shown to act at the hypothalamic level by reducing the rate of episodic discharge of gonadotropin-releasing hormone (GnRH) (10). However, in intact model such as human subjects, the site of action of steroids on the hypothalamic-pituitary axis is difficult to define with such precision (11). Although a hypothalamic level of activity is likely for $\mathrm{P}$, a concomitant effect of $\mathrm{P}$ directly upon the pituitary is not precluded. Simultaneous measurements of hypothalamic GnRH via a push-pull system and peripheral plasma LH levels in the sheep (12) have demonstrated that episodic secretion of GnRH may not always be attended by the appearance of a subsequent episode of LH secretion from the pituitary. Therefore, only limited conclusions regarding GnRH pulse frequency can be inferred from our study.

Our estimation of the extent of the slowing of the pulsatile release of LH in the luteal phase is less marked than previously reported $(3,4)$. This difference can be ascribed to the new finding of several LH pulses of smaller amplitude $(<5 \mathrm{mIU} / \mathrm{ml})$ coexisting with larger LH pulsations during the same study (Fig. 2). In fact, if only the larger LH pulses $(>5 \mathrm{mIU} / \mathrm{ml})$ are considered, the $\mathrm{LH}$ interpulse interval increased to $327 \mathrm{~min}$ in the MLP and $313 \mathrm{~min}$ in the LLP. The subtle differences in LH interpulse interval estimates between our study and that of previous reports $(3,4)$ probably results from the less frequent blood sampling utilized by previous investigators (15-20 $\mathrm{min}$ ), the more limited periods of observation (6-8 h of sampling), and the fewer subjects studied. All of these factors may be possible sources of underestimation in the detection of smaller gonadotropin pulsations. Furthermore, Yen et al. (3) defined their LH pulses as increments in plasma levels $>5 \mathrm{mIU} / \mathrm{ml}$, therefore automatically eliminating small amplitude LH pulsations.

Although the mean amplitude of LH pulses is also progressively reduced across the luteal phase, this change is not correlated with the day of the luteal phase nor with the mean $P$ or $E_{2}$ levels of that day. However, the mean $\mathrm{LH}$ pulse amplitude is heavily influenced by the occurrence of small (i.e., $<5 \mathrm{mIU} /$ $\mathrm{ml}$ ) amplitude pulsations. The incidence of these smaller pulsations is not random across the luteal phase, but reaches its maximum in the MLP and is significantly correlated with the mean $P$ and $E_{2}$ levels of the day of the 24-h study (Fig. 1) and not with the day of the luteal phase. Furthermore, a striking bimodal distribution of LH pulse amplitude is observable in 

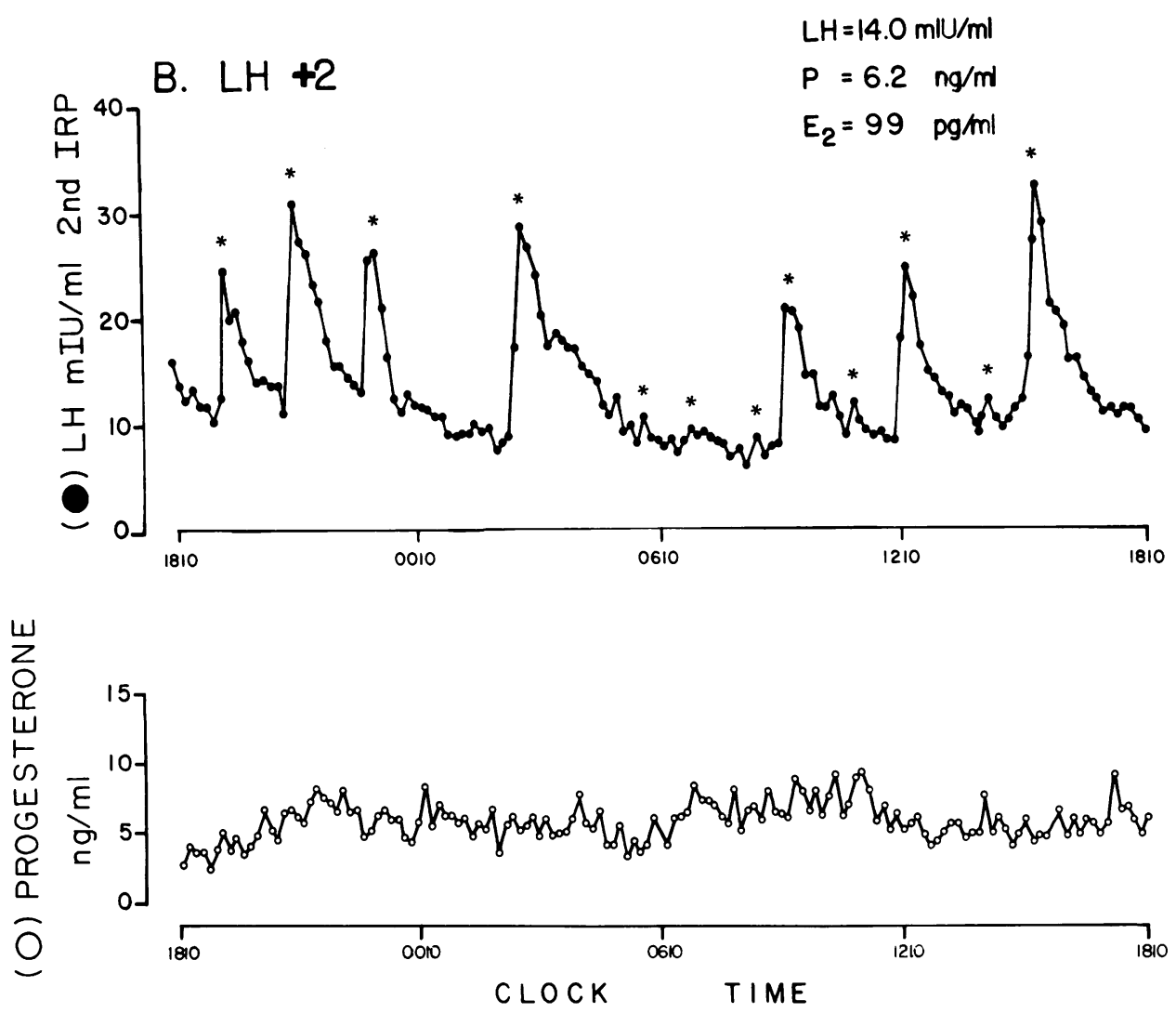

Figure 4. Plasma concentrations of LH (•) and P (0) during $24 \mathrm{~h}$ of blood sampling at 10 -min intervals in volunteer $B$, who was studied in the ELP (LH mid cycle surge +2 d). The mean $\mathrm{LH}, \mathrm{E}_{2}$, and $\mathrm{P}$ concentrations on the day of the study are shown in the upper right hand corner. Asterisks indicate significant LH pulsations. No correlation exists between the $\mathrm{LH}$ and $\mathrm{P}$ data series in this subject.

the MLP, with $52 \%$ of $\mathrm{LH}$ pulses being $<5 \mathrm{mIU} / \mathrm{ml}$ and $30 \%$ $>15 \mathrm{mIU} / \mathrm{ml}$ (Fig. 3). The concomitant occurrence of $\mathrm{LH}$ pulses of heterogeneous amplitude in the course of a few hours may reflect GnRH pulses of differing magnitude, or alternatively, intermittent changes in pituitary sensitivity to GnRH pulsations of equal size. Such a possible pituitary site of action of $P$ has been suggested by previous in vitro and in vivo studies. The addition of $P$ to pituitary cell cultures $(13,14)$ is capable of acutely blocking the increase in gonadotroph sensitivity induced by estrogens. Although small amounts of $P$ can increase pituitary sensitivity when administered after chronic exposure to high estrogen levels $(15,16)$, simultaneous $P$ and estrogen administration is capable of blocking the positive feedback effect of estrogen on gonadotropins (15). Finally, P administration to monkeys receiving chronic treatment with exogenous GnRH administered in a pulsatile fashion will suppress $E_{2}$ benzoateinduced positive feedback on gonadotropins (17). These studies indicate, therefore, that in certain circumstances $P$ may have a direct pituitary effect in blunting the transformation of the $\mathrm{GnRH}$ signal into anterior pituitary gonadotropin pulses. $E_{2}$ acts at the pituitary level by increasing its sensitivity to $\mathrm{GnRH}$ stimulation in a dose- and time-related fashion (18). Therefore, the existence of a positive correlation between $E_{2}$ levels and the occurrence of smaller amplitude LH pulsations is likely to be an indirect result of the parallel secretion of both steroids from the CL (19), as indicated by the excellent $(r=0.81)$ correlation existing between $E_{2}$ and $P$ levels on the days of the 24-h study.

The present study suggests therefore that the frequency and amplitude of $\mathrm{LH}$ pulsations are separately modulated as attested to by their independent changes across the luteal phase. LH frequency is significantly correlated with the day of the luteal phase, while the incidence of LH pulses of smaller amplitude is highest in the MLP in parallel with peak plasma P levels (Figs. 1 and 3). This discordancy in patterns may indicate that modifications in LH pulse frequency are due to chronic exposure to $\mathrm{P}$, while alteration in $\mathrm{LH}$ pulse amplitude are influenced by acute changes in $P$ levels. These results are compatible then with $P$ having a hypothalamic effect upon frequency as well as an independent pituitary site of action which affects the amplitude of each GnRH-induced LH pulse.

The difficulty in the identification of episodic discharge of FSH has plagued most previous studies of gonadotropin secretion in the menstrual cycle. The longer half-life of FSH (20) results in a more stable pattern of peripheral plasma levels of this glycoprotein. Consequently, the resulting small ratio between the amplitude of each discrete burst of FSH secretion and its mean circulating level is an obstacle to the recognition of episodic FSH secretion. Therefore, methods of pulse identification based upon increments from base line which exceed a preset threshold are of limited value in the separation of the FSH signal (i.e. a 


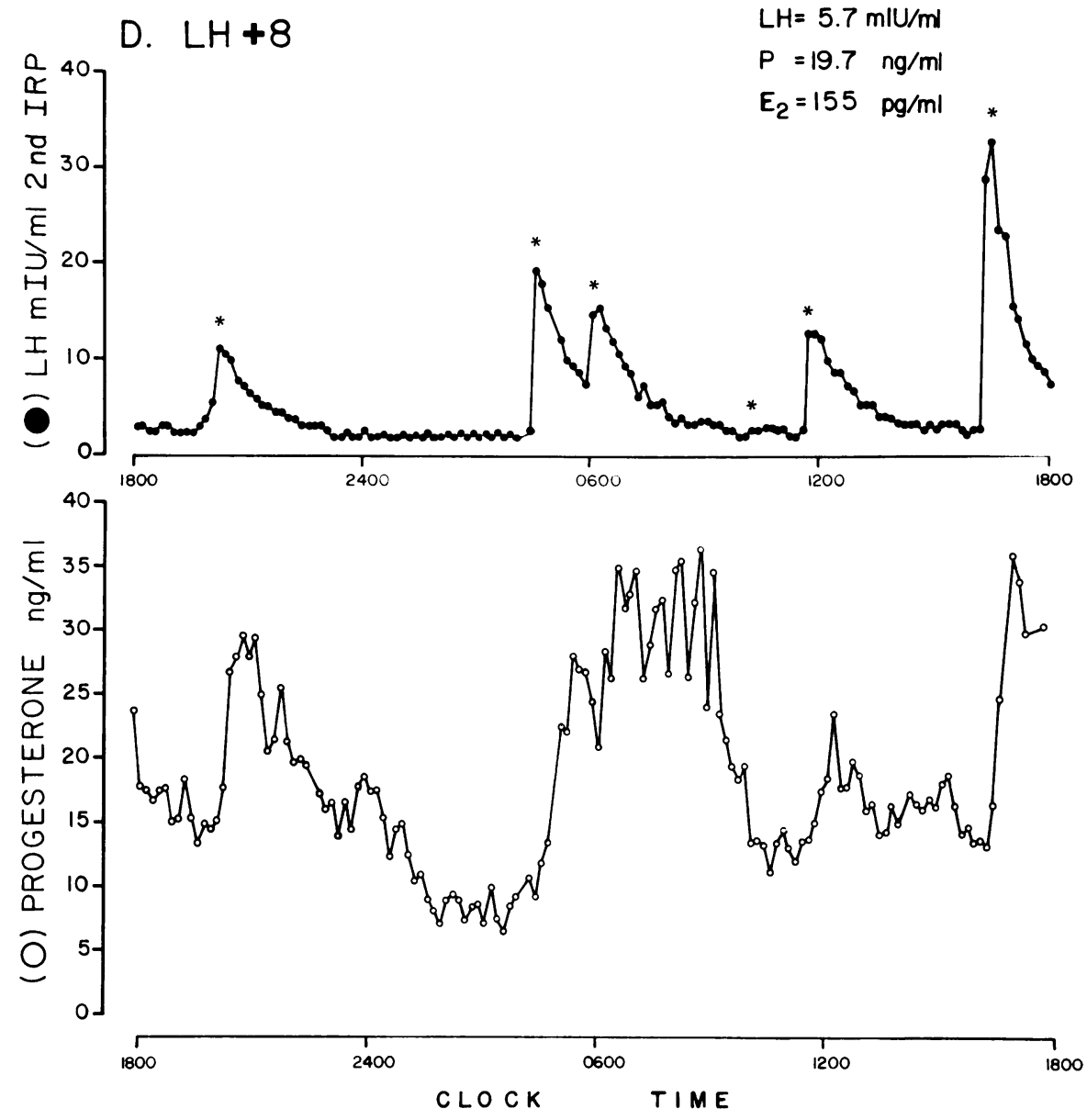

Figure 5. Plasma concentrations of LH (๑) and $P(0)$ during $24 \mathrm{~h}$ of blood sampling at 10 -min intervals in volunteer $\mathrm{D}$, who was studied in the MLP (LH mid cycle surge $+8 \mathrm{~d}$ ). The mean $\mathrm{LH}, \mathrm{E}_{2}$, and $\mathrm{P}$ concentrations on the day of the study are shown in the upper right hand corner. Asterisks indicate significant $\mathrm{LH}$ pulsations. The cross-correlation between $\mathrm{LH}$ and $\mathrm{P}$ in this subject is significant $(P<0.05)$ at $+30-40$ min. pulse) from the noise of the system. More sophisticated mathematical approaches may well be required for recognition of the basic pattern of FSH release. The use of time series analysis has permitted identification of a concordancy in the release of LH and FSH in the male monkey (21) and in the human female (22). In our study, the use of cross-correlation analysis demonstrates a significant relationship between LH and FSH levels predominantly at a time lag of $0 \mathrm{~min}$. The existence of this type of correlation usually indicates that a common stimulatory event precedes the modification encountered in both data series (LH and FSH). Furthermore, a significant cross-correlation exists between FSH and P levels at a time lag of 20-30 $\mathrm{min}$ in the four subjects in the MLP and LLP. This latter phenomenon is likely to be an indirect consequence of the relationship between LH and FSH. Although the issue of FSH control is far from being solved, our findings confirm that LH and FSH are secreted simultaneously. As such they provide yet another line of indirect evidence that GnRH plays an essential role in the regulation of both gonadotropins.

The existence of variable plasma levels of $P$ in the luteal phase has previously been suggested in ewes $(23,24)$ and humans
$(25,26)$. McNatty et al. (23) demonstrated the presence of unstable plasma $P$ concentrations in the course of $24 \mathrm{~h}$ in the sheep. However, plasma LH levels were not measured and therefore no conclusions could be drawn as to the mechanism of this phenomenon. No correlation between LH and P levels was found by Younglai et al. (25) who obtained blood samples for $\mathbf{8 h}$ at $20 \mathrm{~min}$ intervals from six women in the luteal phase. However, these authors reported that most of their LH values were very low or actually beneath the sensitivity of their assay. Baird et al. (24) studied five ewes with utero-ovarian autotransplants on three separate occasions in the luteal phase by drawing blood samples at 10-min intervals for $2 \mathrm{~h}$. No relationship was found between $\mathrm{LH}$ and $\mathrm{P}$ levels in this experiment, despite a prompt response of androstenedione and $E_{2}$ to gonadotropin stimulation. However, the brief periods of observation $(2 \mathrm{~h})$ are likely to have limited the identification of both the LH signal and the $P$ response in this study. On the other hand, it is also possible that the sheep CL is less sensitive than that of the human to LH stimulation as indicated by the high LH dose required to elicit a significant $P$ increment in this animal (27). Recently, Backstrom et al. (26) reported that serum $P$ levels 


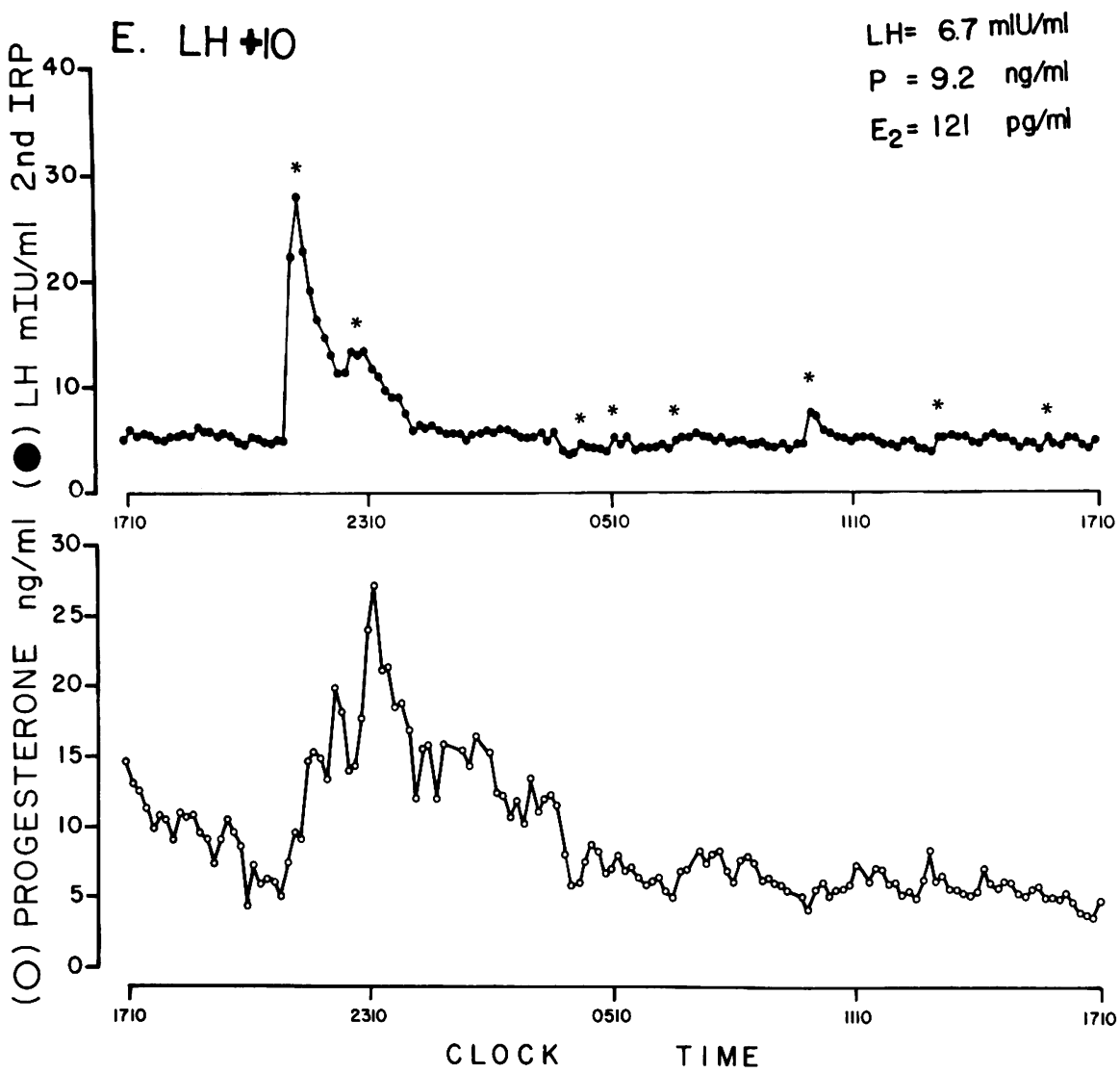

Figure 6. Plasma concentrations of $\mathrm{LH}(\bullet)$ and $\mathrm{P}(\mathrm{O})$ during $24 \mathrm{~h}$ of blood sampling at 10 -min intervals in volunteer $\mathrm{E}$, who was studied in the LLP (LH mid-cycle surge $+10 \mathrm{~d})$. The mean $\mathrm{LH}, \mathrm{E}_{2}$, and $\mathrm{P}$ concentrations on the day of the study are shown in the upper right hand corner. Asterisks indicate significant $\mathrm{LH}$ pulsations. The cross-correlation between $\mathrm{LH}$ and $\mathrm{P}$ in this subject is significant $(P<0.05)$ at $+50-60$ $\min$. increase in response to endogenous LH pulses in the ELP and MLP of the human female. These investigators studied five women in the ELP and MLP and two women in the LLP for $6 \mathrm{~h}$. The P pulsations which they identified in the ELP and MLP, although apparently related in most cases (75\%) to LH secretion, are of much smaller amplitude $(2.0 \pm 0.4 \mathrm{ng} / \mathrm{ml})$ than the very large $P$ increments (up to $40 \mathrm{ng} / \mathrm{ml}$ ) described in our series. Furthermore, no distinction in $\mathrm{P}$ secretion is made between the ELP and the MLP and the pattern of P in the LLP is not mentioned in this report.

An intermittent pattern of LH stimulation of the CL may well be essential for its physiologic secretion of $P$ in view of the observation that continuous LH infusion in the sheep is attended by a prompt increment of $P$ secretion, following which $P$ levels return to base line within $1 \mathrm{~h}$, presumably secondary to desensitization of the CL by LH (27). However, contradictory information exists in the literature as to the role of gonadotropins in the formation, support, and demise of the CL. In the subhuman primate, the affinity of $\mathrm{LH}$ receptors in the $\mathrm{CL}$ does not change across the luteal phase, while their number reaches a peak in the MLP and then declines (28). However, changes in $P$ secretion in the luteal phase precede any modification of LH receptor concentrations, suggesting a relative dissociation of $\mathbf{P}$ production from gonadotropin receptor stimulation. Similarly, administration of an $\mathrm{LH}$ antiserum to rabbits does not affect the CL if given in the ELP (29). In primates, hCG (30) and GnRH analogue (31) administration in ELP (days 1-4 postLH surge) do not cause changes in P levels. This apparent insensitivity of the early CL to LH is also suggested by our findings. Both subjects studied in the ELP demonstrated no correlation between mean plasma $\mathrm{LH}$ and $\mathrm{P}$ levels and no apparent response of the CL to the large endogenous LH pulses (Fig. 4). Another explanation for this finding, however, is that the proximity of LH pulsations in the ELP may cause partial "desensitization" of the CL. Alternatively, input of sufficiently frequent trophic stimuli could result in nearly continuous secretion of $P$ from the $\mathrm{CL}$ and thus obscure a pulsatile pattern of $\mathrm{P}$ secretion. A similar phenomenon of LH pulse slowing unmasking episodic gonadal steroid secretion has been observed in males in whom fluoxymesterone induced a slowed LH frequency and resulted in the emergence of a one-to-one correspondence of $\mathrm{LH}$ pulses and episodic testosterone release from the Leydig cell (32).

In contradistinction to the ELP, administration of hCG to monkeys (30) and of GnRH (33) and its agonists (31) to women at later stages of the luteal phase causes prompt increments in plasma $\mathrm{P}$ concentrations. The appearance of $\mathrm{CL}$ sensitivity to gonadotropins in this part of the cycle is also demonstrated by the acquired $\mathrm{CL}$ responsiveness to endogenous $\mathrm{LH}$ pulsations observed in our subjects in the MLP and LLP (Figs. 5 and 6). High doses of GnRH and its agonistic analogues are capable 
of disrupting $\mathrm{CL}$ function and causing premature luteolysis (31, 33) when administered during the MLP and LLP. On the other hand, the administration of a GnRH antagonist to Rhesus monkeys in the LP does not seem to affect CL function in spite of a significant suppression of gonadotropin levels (2).

In the four subjects we studied in the MLP and LLP, P levels demonstrated large fluctuations over the 24-h study period. Plasma $P$ concentrations in the same 24-h period ranged from as low as $2.3 \mathrm{ng} / \mathrm{ml}$ to peaks of $40.1 \mathrm{ng} / \mathrm{ml}$. Although the average time lag between peak LH and P secretion, as shown by crosscorrelation analysis, ranged between 20 and $60 \mathrm{~min}$, the response of $\mathrm{P}$ to $\mathrm{LH}$ increments was almost immediate and in good agreement with previous studies employing continuous LH infusions (27). Thus, this pattern of $P$ secretion closely reflects episodic LH release; however, LH pulses of similar amplitude in the same individual appear to be associated with differing $P$ responses from their CL (Fig. 5), particularly in the slope of the decay of the $\mathbf{P}$ peak. Moreover, discrete elevations of $\mathbf{P}$ levels were occasionally observed with an apparent lack of a previous LH pulsation (Fig. 5). Such patterns may indicate that, at times, discrepancies may exist between the bioactivity of circulating LH and its immunoactivity, as measured by RIA. Consequently, the measurement of pulsatile $P$ from the human $C L$ may represent the "ultimate" homologous in vivo bioassay for LH. Alternatively, some vestige of $C L$ autonomy could remain in the MLP and LLP and be represented by these "autonomous" episodes of P secretion without antecedent $\mathrm{LH}$ pulses.

The finding of rapidly fluctuating P levels in the MLP and LLP of normal subjects raises the question of the value of a single $P$ estimation in the assessment of luteal phase function. Our results clearly indicate that mid-luteal $\mathbf{P}$ levels previously considered incompatible with an adequate luteal phase $(34,35)$ may be detected in the course of a normal luteal phase. Finally, the prompt and direct response of P to LH pulses in the MLP and LLP suggests that despite its partial autonomy from pituitary activity, the human $C L$ requires intermittent stimulation of $\mathrm{LH}$ to fully express its endocrine potential.

\section{Acknowledgments}

The hCG used for radioactive labeling in the LH assay was kindly provided by Dr. Robert Canfield. We wish to acknowledge the excellent technical skills of Steve Trigilio, Judy Donnelly, Katherine Rogers, Jan Campbell, Carolyn Albers, and Birgit Keller in the performance of the radioimmunoassays; of Donna Beardsworth for the coordination of the clinical studies; and of Nancy Delaney-Perry and Lyn Russo for typing the manuscript. We are grateful to the nursing and administrative personnel of the Clinical Research Center (Mallinckrodt Unit) of the Massachusetts General Hospital for the careful and patient execution of the blood sampling protocols, and to Dr. Robert Neer for his continued support of these studies.

\section{References}

1. Rothchild, I. 1981. The regulation of the mammalian corpus luteum. Rec. Prog. Horm. Res. 37:183-298.
2. Balmaceda, J. P., M. R. Borghi, D. H. Coy, A. V. Schally, and R. H. Asch. 1983. Suppression of postovulatory gonadotropin levels does not affect corpus luteum function in Rhesus monkeys. J. Clin. Endocrinol. Metab. 57:866-868.

3. Yen, S. S. C., C. C. Tsai, F. Naftolin, G. Vandenberg, and L. Ajabor. 1972. Pulsatile patterns of gonadotropin release in subjects with and without ovarian function. J. Clin. Endocrinol. Metab. 34:671-675.

4. Santen, R. J., and C. W. Bardin. 1973. Episodic luteinizing hormone secretion in man. Pulse analysis, clinical interpretation, physiologic mechanism. J. Clin. Invest. 52:2617-2628.

5. Sargent, D. W. 1963. Weight-height relationship of young men and women. Am. J. Clin. Nutr. 13:318-325.

6. Ying, S. Y., and R. Guillemin. 1979. Dried Staphylococcus aureus as a rapid immunological separating agent in radioimmunoassays. $J$. Clin. Endocrinol. Metab. 48:360-362.

7. Merriam, G. R., and K. W. Wachter. 1982. Algorithms for the study of episodic hormone secretion. Am. J. Physiol. 243:E310-318.

8. Clifton, D. K., and R. A. Steiner. 1983. Cycle detection: a technique for estimating the frequency and amplitude of episodic fluctuations in blood hormone and substrate concentration. Endocrinology. 112:10571064.

9. Box, G. E. P., and G. M. Jenkins. 1976. Time Series Analysis, Forecasting and Control. Holden-Day Inc., Oakland, CA.

10. Goodman, R. L., and F. J. Karsch. 1980. Pulsatile secretion of luteinizing hormone: differential suppression by ovarian steriods. Endocrinology. 107:1286-1290.

11. Soules, M. R., R. A. Steiner, D. K. Clifton, W. J. Bremmer, and S. Aksel. 1983. Progesterone modulation of pulsatile luteinizing hormone (LH) secretion in normal women. Society for Gynecologic Investigation, Thirteenth Annual Meeting, Washington, DC. Abstract 453.

12. Levine, J. E., K. F. Pau, V. D. Ramirez, and G. L. Jackson. 1982. Simultaneous measurement of luteinizing hormone-releasing hormone release in the unanesthetized, ovariectomized sheep. Endocrinology. 111:1449-1455.

13. Padmanabhan, V., and E. M. Convey. 1981. Progesterone inhibits the ability of estradiol to increase basal and luteinizing hormone-releasing hormone-induced luteinizing hormone release from bovine pituitary cells in culture: neither progesterone nor estradiol affects follicle-stimulating hormone release. Endocrinology. 109:1091-1096.

14. Drouin, J., and F. Labrie. 1981. Interactions between 17betaestradiol and progesterone in the control of luteinizing hormone and follicle stimulating hormone release in rat anterior pituitary cells in culture. Endocrinology. 108:52-57.

15. March, C. M., U. Goebelsmann, R. M. Nakamura, and D. R. Mishell, Jr. 1979. Roles of estradiol and progesterone in eliciting midcycle luteinizing hormone and follicle-stimulating hormone surges. J. Clin. Endocrinol. Metab. 49:507-513.

16. Lasley, B. L., C. F. Wang, and S. S. C. Yen. 1975. The effects of estrogen and progesterone on the functional capacity of the gonadotroph. J. Clin. Endocrinol. Metab. 41:820-826.

17. Pohl, C. R., D. W. Richardson, G. Marshall, and E. Knobil. 1982. Mode of action of progesterone in the blockade of gonadotropin surges in the Rhesus monkey. Endocrinology. 110:1454-1455.

18. Kamel, F., and L. C. Krey. 1982. Gonadal steroid modulation of LHRH-stimulated LH secretion by pituitary cell cultures. Mol. Cell. Endocr. 26:151-164.

19. Aedo, A. R., P. H. Pedersen, S. C. Pedersen, and E. Diczfalusy. 1980. Ovarian steriod secretion in normally menstruating women. II. The contribution of the corpus luteum. Acta Endocrinol. 95:222-231.

20. Yen, S. S. C., L. A. Llerena, O. H. Pearson, and A. S. Littell. 
1970. Disappearance rates of endogenous follicle-stimulating hormone in serum following surgical hypophysectomy in men. Clin. Endocrinol. 30:325-329.

21. Bercu, B. B., B. C. Lee, J. L. Pineda, B. E. Spiliotis, D. W. Denman, H. J. Hoffman, T. J. Brown, and H. C. Sachs. 1983. Male sexual development in the moneky. I. Cross-sectional analysis of pulsatile hypothalamic-pituitary-testicular function. J. Clin. Endocrinol. Metab. 56:1214-1226.

22. Filicori, M., M. Marseguerra, P. Mimmi, G. Bolelli, F. Franceschetti, G. Possati, and C. Flamigni. 1982. The pattern of LH and FSH pulsatile release: physiological and clinical significance. In The Gonadotropins: Basic Science and Clinical Aspects in Females. C. Flamigni and J. R. Givens, editors. Academic Press, London. 365-375.

23. McNatty, K. P., K. J. A. Revfeim, and A. Young. 1973. Peripheral plasma progesterone concentrations in sheep during the oestrous cycle. J. Endocrinol. 58:219-225.

24. Baird, D. T., I. A. Swanston, and R. J. Scaramuzzi. 1976. Pulsatile release of $\mathbf{L H}$ and secretion of ovarian steroids in sheep during the luteal phase of the estrous cycle. Endocrinology. 98:1490-1496.

25. Younglai, E. V., S. L. Smith, J. M. Cleghorn, and R. F. Streiner. 1975. Variation in ovarian steroid levels during the luteal phase of the menstrual cycle. Clin. Biochem. 8:234-239.

26. Backstrom, C. T., A. S. McNeilly, R. M. Leask, and D. T. Baird. 1982. Pulsatile secretion of LH, FSH, prolactin, oestradiol and progesterone in the human menstrual cycle. Clin. Endocrinol. 17:29-42.

27. Collett, R. A., R. B. Land, and D. T. Baird. 1973. The pattern of progesterone secretion by the autotransplanted ovary of the ewe in response to ovine luteinizing hormone. J. Endocrinol. 56:403-411.
28. Cameron, J. L., and R. L. Stouffer. 1982. Gonadotropin receptors in the primate corpus luteum. II. Changes in available luteinizing hormone- and chorionic-gonadotropin-binding sites in macacque luteal membranes during the nonfertile menstrual cycle. Endocrinology. 110:2068-2073.

29. Spies, H. G., and S. K. Quadri. 1967. Regression of corpora lutea and interruption of pregnancy in rabbits following treatment with rabbit serum to ovine LH. Endocrinology. 80:1127-1132.

30. Wilks, J. W., and A. S. Noble. 1983. Steroidogenic responsiveness of the monkey corpus luteum to exogenous chorionic gonadotropin. Endocrinology. 112:1256-1266.

31. Lemay, A., N. Faure, F. Labrie, and A. T. A. Fazekas. 1983 Gonadotroph and corpus luteum responses to two successive intranasal doses of a luteinizing hormone releasing agonist at different days after the midcycle luteinizing hormone surge. Fertil. Steril. 39:661-667.

32. Vigersky, R. A., R. B. Easley, and D. L. Loriaux. 1976. Effect of fluoxymesterone on the pituitary-gonadal axis: the role of testosteroneestradiol binding globulin. J. Clin. Endocrinol. Metab. 43:1-9.

33. Lemay, A., F. Labrie, L. Ferland, and J. P. Raynaud. 1979. Possible luteolytic effects of luteinizing hormone-releasing hormone in normal women. Fertil. Steril. 31:29-34.

34. Abraham, G. E., W. D. Odell, R. S. Swerdloff, and K. Hopper. 1972. Simultaneous radioimmunoassay of plasma FSH, LH, progesterone, 17-hydroxyprogesterone and estradiol-17beta during the menstrual cycle. J. Clin. Endocrinol. Metab. 34:312-318.

35. Israel, R., D. R. Mishell, S. C. Stone, I. H. Thorneycroft, and D. L. Moyer. 1972. Single luteal phase serum progesterone assay as an indicator of ovulation. Am. J. Obstet. Gynecol. 112:1043-1046. 